\title{
Attitudes towards seclusion and restraint in mental health settings: findings from a large, community- based survey of consumers, carers and mental health professionals
}

\author{
S. A. Kinner ${ }^{1,2,3,4,5 *}$, C. Harvey ${ }^{6,7}$, B. Hamilton ${ }^{8,9}$, L. Brophy ${ }^{2,10}$, C. Roper ${ }^{11}$, B. McSherry ${ }^{12}$ and \\ J. T. Young $2,13,14$ \\ ${ }^{1}$ Griffith Criminology Institute and Menzies Health Institute Queensland, Griffith University, Brisbane, Australia \\ ${ }^{2}$ Melbourne School of Population and Global Health, University of Melbourne, Australia \\ ${ }^{3}$ Mater Research Institute, University of Queensland, Brisbane, Australia \\ ${ }^{4}$ School of Public Health and Preventive Medicine, Monash University, Melbourne, Australia \\ ${ }^{5}$ Centre for Adolescent Health, Murdoch Childrens Research Institute, Melbourne, Australia \\ ${ }^{6}$ Department of Psychiatry, University of Melbourne, Australia \\ ${ }^{7}$ North Western Area Mental Health Services, Melbourne, Australia \\ ${ }^{8}$ Department of Nursing, University of Melbourne, Australia \\ ${ }^{9}$ St Vincent's Mental Health, Melbourne, Australia \\ ${ }^{10}$ Mind Australia, Melbourne, Australia \\ ${ }^{11}$ Centre for Psychiatric Nursing, University of Melbourne, Australia \\ ${ }^{12}$ Melbourne Social Equity Institute, University of Melbourne, Australia \\ ${ }^{13}$ Centre for Health Services Research, The University of Western Australia, Perth, Australia \\ ${ }^{14}$ National Drug Research Institute, Curtin University, Perth, Australia
}

\begin{abstract}
Aims. There are growing calls to reduce, and where possible eliminate, the use of seclusion and restraint in mental health settings, but the attitudes and beliefs of consumers, carers and mental health professionals towards these practices are not well understood. The aim of this study was to compare the attitudes of mental health service consumers, carers and mental health professionals towards seclusion and restraint in mental health settings. In particular, it aimed to explore beliefs regarding whether elimination of seclusion and restraint was desirable and possible.
\end{abstract}

Methods. In 2014, an online survey was developed and widely advertised in Australia via the National Mental Health Commission and through mental health networks. The survey adopted a mixed-methods design, including both quantitative and qualitative questions concerning participants' demographic details, the use of seclusion and restraint in practice and their views on strategies for reducing and eliminating these practices.

Results. In total 1150 survey responses were analysed. A large majority of participants believed that seclusion and restraint practices were likely to cause harm, breach human rights, compromise trust and potentially cause or trigger past trauma. Consumers were more likely than professionals to view these practices as harmful. The vast majority of participants believed that it was both desirable and feasible to eliminate mechanical restraint. Many participants, particularly professionals, believed that seclusion and some forms of restraint were likely to produce some benefits, including increasing consumer safety, increasing the safety of staff and others and setting behavioural boundaries.

Conclusions. There was strong agreement across participant groups that the use of seclusion and restraint is harmful, breaches human rights and compromises the therapeutic relationship and trust between mental health service providers and those who experience these restrictive practices. However, some benefits were also identified, particularly by professionals. Participants had mixed views regarding the feasibility and desirability of eliminating these practices.

Received 23 February 2016; Accepted 13 July 2016; First published online 12 August 2016

Key words: Mental health, restraint, restrictive practices, seclusion, survey.

\footnotetext{
*Address for correspondence: Professor S. Kinner, Griffith Criminology Institute, Griffith University, 176 Messines Ridge Rd., Mt Gravatt QLD 4122, Australia.

(Email: s.kinner@unimelb.edu.au)
}

\section{Introduction}

There is growing international impetus to reduce and eliminate restrictive practices in mental health settings (McSherry, 2008; McSherry \& Gooding, 2013). This has arisen through consumer and carer advocacy and is

This is an Open Access article, distributed under the terms of the Creative Commons Attribution licence (http://creativecommons.org/licenses/by/ $4.0 /)$, which permits unrestricted re-use, distribution, and reproduction in any medium, provided the original work is properly cited. 
increasingly supported by efforts to improve practice and policy (Huckshorn, 2004; National Mental Health Consumer and Carer Forum, 2009). The coming into force in 2008 of the United Nations Convention on the Rights of Persons with Disabilities has added further weight to initiatives targeting reducing restrictive practices (McSherry, 2008).

Seclusion and restraint are interventions, which are currently permitted for use in mental health services and other settings to control or manage a person's behaviour. Seclusion generally refers to the deliberate confinement of a person in a room or area that he or she cannot freely exit. The term 'restraint' may encompass the use of bodily force (physical restraint) or a device to control a person's freedom of movement (mechanical restraint) and/or the use of medication to control a person's behaviour rather than to treat a mental disorder (chemical restraint). Mental health consumers and carers in particular also use the term 'emotional restraint' to refer to situations where mental health consumers feel constrained from expressing their views openly and honestly to health practitioners or behaving in particular ways for fear of the consequences (National Mental Health Consumer and Carer Forum, 2009; Roper et al. 2015). Of all the forms of restrictive practices, emotional restraint has the least clarity and agreement in terms of definition (Roper et al. 2015).

The use of seclusion and restraint has been the subject of increasing attention from consumer, carer and professional bodies and policymakers. In 2010, The Royal Australian and New Zealand College of Psychiatrists stated that it was 'committed to achieving the aim of reducing, and where possible eliminating, the use of seclusion and restraint in a way, which supports good clinical practice and provides safe and improved care for consumers' (2010). In Australia, one of ten key recommendations made by the National Mental Health Commission (2012) was to 'reduce the use of involuntary practices and work to eliminate seclusion and restraint' and, in New Zealand, Te Pou Te Whakaaro Nui (the National Centre of Mental Health Research, Information and Workforce Development) has set out a framework for 'best practice' in the reduction and elimination of seclusion and restraint (O'Hagan et al. 2008).

Most literature on restrictive interventions concentrates on the reduction rather than the elimination of seclusion and/or restraint. In 2005, the National Association of State Mental Health Program Directors in the United States released a document entitled 'Six Core Strategies to Reduce the Use of Seclusion and Restraint' (2008). These strategies, which include leadership towards organisational change and workforce development and training, have been influential in practice. In the USA, decreases in seclusion and restraint rates have been reported from 70 facilities that have used these strategies; reductions range from 47 to $92 \%$ (LeBel et al. 2004; Smith et al. 2005; Sullivan et al. 2005; Barton et al. 2009; Lewis et al. 2009). In a Finnish cluster randomised controlled trial (RCT), the six core strategies were tested leading to reduction in the incidence of seclusion and restraint from 30 to $15 \%$ of total patient time in the intervention wards in a forensic hospital (Putkonen et al. 2013). In England, the Safewards model (Bowers, 2014) has identified aspects of working in psychiatric wards that are known to create potential 'flashpoints' and strategies to manage these. Safewards was subject to a cluster RCT, which indicated that acute inpatient staff can successfully intervene to manage those flashpoints to reduce conflict and use of seclusion (Bowers et al. 2015). This model has recently been trialled in Australia and evaluation is pending.

Little has been written about whether or how seclusion and restraint can be eliminated entirely. Only one non peer-reviewed book (Murphy \& BenningtonDavis, 2005) refers to a model for eliminating the use of seclusion and restraint, and the feasibility of implementing this model in acute mental health settings has not been tested. This is despite a number of studies noting adverse consequences for those subjected to seclusion and mechanical restraint (Burns \& Rose, 2013; Gerace et al. 2014) and concerns with human rights breaches (Kumble \& McSherry, 2010).

As part of a larger study conducted by the Melbourne Social Equity Institute, University of Melbourne and funded by the Australian National Mental Health Commission, an anonymous online survey was designed to identify and assess options to reduce and eliminate seclusion and restraint, and to consider their perceived desirability and feasibility. Using a nationwide promotion and recruitment strategy, the survey targeted key personnel in hospitals, custodial and ambulatory settings, as well as individuals with lived experience, their carers, family members and support persons. In this paper we examine participants' perspectives in relation to the benefits and harms of seclusion and restraint as well as feasibility and desirability of eliminating seclusion and restraint.

\section{Method}

\section{Procedures}

The survey adopted a mixed-methods design, including both quantitative multiple-choice and qualitative open-ended questions. It was promoted via email distribution lists, discussion forums, appropriate 
websites, the media, individual networks, relevant newsletters and stakeholders identified through the project. It was advertised via the Melbourne Social Equity Institute's website and the website of the National Mental Health Commission. The survey was hosted on the online platform SurveyMonkey ${ }^{\circledR}$ and was open from 19 March to 17 May 2014. The survey received approval from the University of Melbourne's School of Population and Global Health Human Ethics Advisory Group and Health Sciences Human Ethics Sub-Committee.

\section{Participants}

People aged 18 years or older who were interested in commenting on seclusion and restraint were invited to complete the survey. The survey was open to the general public because a wide range of people in the community has experience with mental health service provision and may have experiences with the use of seclusion and restraint.

Based on responses to a multiple-choice question about the nature of their connection to the topic, participants were categorised into three mutually exclusive groups: (1) lived experience of treatment for a mental health issue (consumers); (2) lived experience of caring for someone with a mental health issue, but no personal experience of treatment for a mental health issue (carers); and (3) experience of encountering people with mental health issues in a professional or support capacity, but no lived experience as a consumer or carer (for simplicity, referred to hereafter as professionals).

\section{Measures}

The survey included questions about demographic characteristics, experiences related to mental illness and restrictive practices, and attitudes and beliefs regarding the use of restrictive practices in mental health settings. Development of the survey was informed by a comprehensive review of the literature, consultation with key experts in the mental health sector and guidance from consumer and carer expert advisory groups. Definitions for each form of restrictive practice (physical restraint, mechanical restraint, chemical restraint, emotional restraint and seclusion) were provided.

Emotional restraint was included in the online survey at the instigation of the Australian National Mental Health Commission's Core Reference Group and the Lived Experience Advisory Group constituted for this project. Although less well defined (Roper et al. 2015) and broader in scope than the other forms of restraint, the Australian Government through the
Department of Social Services' National Framework for Reducing and Eliminating the Use of Restrictive Practices in the Disability Service Sector (2014) has pointed to restraint as going beyond physical, mechanical and chemical forms to involve forms of 'powercontrol' strategies. In this study the term 'emotional restraint' refers to situations where mental health consumers feel constrained from expressing their views openly and honestly to health practitioners or behaving in particular ways for fear of the consequences.

The perceived benefits and harms of restrictive practices (physical restraint, mechanical restraint, chemical restraint, emotional restraint and seclusion) were assessed by asking participants how likely it was that each of a list of outcomes would occur if each restrictive practice was used ( 1 = Never, $2=$ Rarely, $3=$ Often, $4=$ Always). The list of potential benefits and harms was developed based on a review of the literature and in consultation with experts and consumer and carer advisory groups. Participants were also asked to indicate whether they thought it was feasible and desirable to eliminate each restrictive practice entirely. With respect to the feasibility of elimination, participants were asked: 'In relation to the care of people experiencing mental health issues, do you believe the following can be completely eliminated from current practice?' (yes/no). With respect to the desirability of elimination, participants were asked 'Which of the following should be completely eliminated from current practice?' (yes/no).

\section{Data management and analysis}

Descriptive statistics were calculated to describe the demographic characteristics of the overall sample and of each subgroup (consumers, carers, professionals). Responses to Likert scale questions about the perceived effects of seclusion and restraint were dichotomised for the purposes of analysis into never/ rarely $v$. often/always. The three benefits and the three harms endorsed by the largest proportion of participants as 'often' or 'always' occurring as a result of each restrictive practice were retained for further analysis.

We calculated the proportion of participants indicating that each benefit and harm would 'often' or 'always' occur as a result of each restrictive practice, and the proportion of participants indicating that it was desirable and feasible to eliminate each form of restrictive practice. Differences between subgroups were examined using chi-square tests.

To examine the association between lived experience and attitudes towards the desirability and feasibility of eliminating seclusion and restraint, we fitted a log-linked modified-Poisson regression as 
recommended previously (Zou, 2004). We calculated prevalence risk ratios (PRRs) with 95\% confidence intervals $(95 \% \mathrm{CI})$, using the 'professional' group (i.e., no lived experience) as the reference category. We also computed adjusted prevalence risk ratios (APRRs) adjusting for gender, age, Indigenous status, state of residency, urbanicity, and education level. Regression s.E. were adjusted for non-random survey sampling using the SVY (survey) prefix command in Stata. Because all questions were optional, the valid sample size varies between items and is shown in all Tables. All analyses were conducted using Stata version 14.1 (StataCorp, 2015).

\section{Results}

A total of 1451 people responded to the survey. Of these, 185 responses were not analysed because the participants were aged below $18(n=4 ; 0.3 \%)$, residing outside of Australia $(n=45 ; 3.1 \%)$ or had not provided consent to the study $(n=136 ; 9.4 \%)$. The small number of overseas participants means that a detailed comparison of overseas and Australian participants was not appropriate. A further $78(5.4 \%)$ responses were excluded due to missing country of residence or participant 'exposure' group data. We excluded responses from $38(2.6 \%)$ participants who did not identify as either a consumer, carer or professional. The remaining $1150(79.3 \%)$ participant responses were retained for analysis.

Table 1 presents the demographic characteristics of the sample. The majority of participants were female and had a tertiary education; relatively few participants were aged under 30 years and 21 participants $(1.9 \%)$ identified as Indigenous. Although the sample included respondents from all Australian states and territories, and from urban, regional and remote areas, the majority of participants lived in a capital city $(62 \%)$ and in Victoria or New South Wales (59\%).

Almost one in two participants $(n=529,46 \%)$ identified as a mental health consumer; $27 \%(n=308)$ identified as a carer and $27 \%(n=313)$ identified as a professional. Compared with the other two groups, consumers were more likely to be female, and were on average younger and less likely to report a tertiary education. Those who identified as professionals were more likely to report a tertiary education and to live in a capital city.

\section{Perceived harms of the use of seclusion and restraint}

The perceived harms of seclusion and restraint most frequently endorsed by participants included infringing human rights, compromising therapeutic trust, and traumatising or triggering past trauma. The majority of participants believed that all forms of restraint and seclusion would often or always cause these forms of harm. Between 80 and $90 \%$ of participants believed that all forms of restraint and seclusion infringed human rights, and with the exception of chemical restraint $(74 \%)$, between 80 and $90 \%$ believed that each form of restrictive practice would often or always compromise therapeutic trust. Just under two thirds $(62 \%)$ believed that chemical restraint would often or always cause trauma or trigger past trauma, while between 80 and $90 \%$ held this view for all other forms of restrictive practice.

Table 2 compares consumer, carer and professional perceptions of harms of each restrictive practice. The group least likely to believe that seclusion and restraint would cause harm was professionals, although the majority of professionals still believed that all forms of restrictive practice except for chemical restraint (49\%) would often or always cause harm. In most cases the proportion of carers perceiving that such practices would cause harm was greater, and the proportion of consumers holding this belief was greater still. Just over two thirds of consumers (69\%) believed that chemical restraint would often or always cause trauma or trigger past trauma.

\section{Perceived benefits of seclusion and restraint}

The perceived benefits of seclusion and restraint most frequently endorsed by participants included increasing consumer safety, increasing the safety of staff and others, and setting behavioural boundaries. Table 3 compares consumer, carer and professional perceptions of the perceived benefits of each restrictive practice. The group most likely to perceive benefits of seclusion and restraint was professionals; in most cases the proportion of carers perceiving benefits was smaller, and the proportion of consumers perceiving benefits smaller still. Nevertheless, the majority of consumers believed that physical, mechanical and chemical restraint, and seclusion, increased the safety of others. By contrast, a minority of consumers (and carers and professionals) believed that emotional restraint increased the safety of others or indeed the consumer (Table 3).

\section{Perceived feasibility and desirability of eliminating seclusion and restraint}

Participants were asked whether they thought it was desirable or feasible to completely eliminate seclusion and restraint (Table 4). The vast majority of participants believed that it was both desirable and feasible to eliminate emotional restraint and mechanical 
Table 1. Sample characteristics by group

\begin{tabular}{|c|c|c|c|c|c|}
\hline Characteristic & $\begin{array}{c}\text { Consumers } n(\%) \\
529(46.0 \%)\end{array}$ & $\begin{array}{l}\text { Carers } n(\%) \\
308(26.8 \%)\end{array}$ & $\begin{array}{c}\text { Professionals } n(\%) \\
313(27.2 \%)\end{array}$ & $\begin{array}{c}\text { Total } \\
N(\%)^{*}\end{array}$ & $p$-value \\
\hline Female & $402(77.3 \%)$ & $216(70.8 \%)$ & $217(70.0 \%)$ & $835(73.6 \%)$ & 0.041 \\
\hline Indigenous & $11(2.1 \%)$ & $8(2.7 \%)$ & $2(0.7 \%)$ & $21(1.9 \%)$ & 0.153 \\
\hline Age category & & & & & $<0.001$ \\
\hline $18-30$ years & $123(23.3 \%)$ & $33(10.7 \%)$ & $41(13.1 \%)$ & 197 (17.1\%) & \\
\hline $31-50$ years & $248(46.9 \%)$ & $115(37.3 \%)$ & $143(45.7 \%)$ & $506(44.0 \%)$ & \\
\hline$>50$ years & $158(29.9 \%)$ & $160(52.0 \%)$ & $129(41.2 \%)$ & 447 (38.9\%) & \\
\hline Education & & & & & $<0.001$ \\
\hline$\leq$ Year 12 & $79(15.0 \%)$ & $33(10.8 \%)$ & $3(0.9 \%)$ & $59(5.2 \%)$ & \\
\hline Diploma/certificate & $135(25.7 \%)$ & $43(14.0 \%)$ & $40(12.9 \%)$ & $218(19.1 \%)$ & \\
\hline Tertiary education & $312(59.3 \%)$ & $230(75.2 \%)$ & $268(86.2 \%)$ & $810(70.9 \%)$ & \\
\hline Remoteness & & & & & 0.021 \\
\hline Capital city & $311(60.4 \%)$ & $173(58.0 \%)$ & $208(68.4 \%)$ & $692(61.9 \%)$ & \\
\hline Regional & $138(26.8 \%)$ & $95(31.9 \%)$ & $73(24.0 \%)$ & $306(27.4 \%)$ & \\
\hline Rural/remote & $66(12.8 \%)$ & $30(10.1 \%)$ & $23(7.6 \%)$ & $119(10.7 \%)$ & \\
\hline State/territory & & & & & 0.104 \\
\hline VIC & $164(32.3 \%)$ & $100(33.8 \%)$ & $96(31.8 \%)$ & $360(32.6 \%)$ & \\
\hline NSW & $145(28.5 \%)$ & $75(25.3 \%)$ & $76(25.2 \%)$ & $296(26.8 \%)$ & \\
\hline QLD & $80(15.8 \%)$ & $35(11.8 \%)$ & $41(13.6 \%)$ & $156(14.1 \%)$ & \\
\hline$\widehat{\text { SA }}$ & $51(10.0 \%)$ & $40(13.5 \%)$ & $44(14.6 \%)$ & $135(12.2 \%)$ & \\
\hline WA & $40(7.9 \%)$ & $20(6.8 \%)$ & $18(6.0 \%)$ & $78(7.0 \%)$ & \\
\hline TAS & $5(1.0 \%)$ & $8(2.7 \%)$ & $4(1.3 \%)$ & $17(1.5 \%)$ & \\
\hline $\mathrm{ACT}$ & $16(3.2 \%)$ & $8(2.7 \%)$ & $8(2.7 \%)$ & $32(2.9 \%)$ & \\
\hline NT & $7(1.4 \%)$ & $10(3.4 \%)$ & $15(5.0 \%)$ & $32(2.9 \%)$ & \\
\hline $\begin{array}{l}\text { Ever observed or affected by the seclusion } \\
\text { and restraint of someone else for a } \\
\text { mental health issue }\end{array}$ & 408 (79.7\%) & $275(89.6 \%)$ & $283(93.1 \%)$ & $966(86.0 \%)$ & $<0.001$ \\
\hline
\end{tabular}

*Due to missing values, sample size ranges from 1106 to 1150 .

restraint; just over half believed that it was both desirable and feasible to eliminate seclusion. By contrast, just over a third of participants believed that it was desirable to eliminate physical and chemical restraint, and around one in four believed that this was feasible. There were marked differences between groups, with consumers most likely and professionals least likely to believe that it was both desirable and feasible to eliminate such practices. The notable exception was emotional restraint, with the vast majority of participants in all groups believing that it was both desirable and feasible to eliminate this practice. Only a small minority of professionals believed that it was feasible to eliminate physical restraint $(14 \%)$ or chemical restraint $(13 \%)$.

Compared with professionals, both carers and consumers were significantly more likely to believe that elimination of chemical restraint and seclusion was both desirable and feasible. Consumers were significantly more likely than professionals to believe that elimination of physical restraint was desirable and feasible. These associations persisted after adjustment for potential confounding factors (Table 5).

\section{Discussion}

In this national survey we found that a large majority of participants believed that seclusion and restraint were likely to cause harm, including breaching human rights, compromising therapeutic trust and potentially causing or triggering past trauma. Evidently, seclusion and restraint are practices of great concern for all stakeholders, and our findings suggest a strong preference for minimising their use in Australia, while pursuing prevention and alternative strategies. However, many participants, particularly professionals, also believed that seclusion and some forms of restraint were likely to produce some benefits, including increasing consumer safety, increasing the safety of staff and others, and setting behavioural boundaries.

While emotional restraint is generally not well defined, and rarely regulated, it appears that many participants did acknowledge this practice and had serious concerns about it. Only a minority of participants believed that this practice resulted in any benefits and the vast majority believed that it was 
Table 2. Perceived harms by group and type of restraint and seclusion

\begin{tabular}{|c|c|c|c|c|c|}
\hline Perceived harms (valid $N, \%$ ) & $\begin{array}{c}\text { Consumers } \\
n(\%)\end{array}$ & $\begin{array}{l}\text { Carers } \\
n(\%)\end{array}$ & $\begin{array}{c}\text { Professionals } \\
n(\%)\end{array}$ & $\begin{array}{l}\text { Total } \\
N(\%)\end{array}$ & $p$-value \\
\hline \multicolumn{6}{|l|}{ Physical restraint } \\
\hline Often/always infringes on human rights $(N=784,68.2 \%)$ & $330(91.7 \%)$ & $190(88.8 \%)$ & $178(84.8 \%)$ & $698(89.0 \%)$ & 0.039 \\
\hline $\begin{array}{l}\text { Often/always traumatises or triggers past trauma } \\
(N=813,70.7 \%)\end{array}$ & $343(91.2 \%)$ & $187(86.6 \%)$ & $191(86.4 \%)$ & $721(88.7 \%)$ & 0.106 \\
\hline $\begin{array}{l}\text { Often/always compromises therapeutic trust } \\
\qquad(N=780,67.8 \%)\end{array}$ & $322(89.2 \%)$ & $179(85.2 \%)$ & $166(79.4 \%)$ & $667(85.5 \%)$ & 0.006 \\
\hline \multicolumn{6}{|l|}{ Mechanical restraint } \\
\hline Often/always infringes on human rights $(N=743,64.6 \%)$ & $308(92.2 \%)$ & $186(89.9 \%)$ & $176(87.1 \%)$ & $670(90.2 \%)$ & 0.156 \\
\hline $\begin{array}{l}\text { Often/always compromises therapeutic trust } \\
\qquad(N=744,64.2 \%)\end{array}$ & $311(91.7 \%)$ & $180(89.1 \%)$ & $170(83.7 \%)$ & $661(88.8 \%)$ & 0.016 \\
\hline $\begin{array}{l}\text { Often/always traumatises or triggers past trauma } \\
\qquad(N=770,66.9 \%)\end{array}$ & $313(88.9 \%)$ & $179(86.9 \%)$ & $182(85.9 \%)$ & $674(87.5 \%)$ & 0.536 \\
\hline \multicolumn{6}{|l|}{ Chemical restraint } \\
\hline Often/always infringes on human rights $(N=771,67.0 \%)$ & $305(86.4 \%)$ & $162(76.8 \%)$ & $147(71.0 \%)$ & $614(79.6 \%)$ & $<0.001$ \\
\hline $\begin{array}{l}\text { Often/always compromises therapeutic trust } \\
\qquad(N=771,67.0 \%)\end{array}$ & $295(82.9 \%)$ & $148(72.2 \%)$ & $130(61.9 \%)$ & $573(74.3 \%)$ & $<0.001$ \\
\hline $\begin{array}{l}\text { Often/always traumatises or triggers past trauma } \\
\qquad(N=791,68.8 \%)\end{array}$ & $251(69.0 \%)$ & $130(61.9 \%)$ & $107(49.3 \%)$ & $488(61.7 \%)$ & $<0.001$ \\
\hline \multicolumn{6}{|l|}{ Emotional restraint } \\
\hline Often/always infringes on human rights $(N=720,62.6 \%)$ & $305(91.0 \%)$ & $174(88.8 \%)$ & $156(82.5 \%)$ & $635(88.2 \%)$ & 0.014 \\
\hline $\begin{array}{l}\text { Often/always compromises therapeutic trust } \\
\qquad(N=722,62.8 \%)\end{array}$ & $307(91.6 \%)$ & $171(86.8 \%)$ & $151(79.5 \%)$ & $629(87.1 \%)$ & $<0.001$ \\
\hline $\begin{array}{l}\text { Often/always traumatises or triggers past trauma } \\
\qquad(\mathrm{N}=750,65.2 \%)\end{array}$ & $320(91.4 \%)$ & $169(85.3 \%)$ & $148(73.3 \%)$ & $637(84.9 \%)$ & $<0.001$ \\
\hline \multicolumn{6}{|l|}{ Seclusion } \\
\hline Often/always infringes on human rights $(N=775,67.4 \%)$ & $323(91.8 \%)$ & $183(85.9 \%)$ & $173(82.4 \%)$ & $679(87.6 \%)$ & 0.003 \\
\hline $\begin{array}{l}\text { Often/always traumatises or triggers past trauma } \\
(N=803,69.9 \%)\end{array}$ & $325(88.3 \%)$ & $179(82.5 \%)$ & $180(82.6 \%)$ & $684(85.2 \%)$ & 0.071 \\
\hline $\begin{array}{l}\text { Often/always compromises therapeutic trust } \\
(N=771,67.0 \%)\end{array}$ & 313 (89.7\%) & $168(80.0 \%)$ & $165(77.8 \%)$ & $646(83.8 \%)$ & $<0.001$ \\
\hline
\end{tabular}

harmful, and that it was feasible and desirable to eliminate its use. Finally, the vast majority of participants believed that it was both desirable and feasible to eliminate mechanical restraint.

There were some notable differences in the responses of participants according to whether they had lived experience. Consumers were more likely than professionals to believe that seclusion and restraint caused harm, although in all groups the vast majority identified harms associated with these practices. This widespread belief identified amongst consumers of the harm inflicted by restrictive practices echoes the findings of Burns \& Rose (2013) that such coercive treatment is experienced by consumers 'as a naked expression of their powerlessness' (p. 88). Conversely, professionals were more likely than consumers to identify benefits associated with restrictive practices. This may be because, for professionals, seclusion and restraint are often viewed through a lens of occupational health and safety, such that restrictive interventions are viewed as a necessary response to behaviours of concern (Chan, 2016). In both cases, the responses of carers fell between those of consumers and professionals on most questions. These findings indicate that, perhaps not surprisingly, people with lived experience are more sensitised to the harms of seclusion and restraint, and less likely to believe that there are benefits to such practices (Brophy et al. 2016a,b).

Notwithstanding the above, the broad agreement on harms associated with restrictive practices across the three surveyed stakeholder groups has not previously been identified. Indeed, earlier research showed strong divergence between views of staff and patients in three acute wards of one service in the USA, with staff expressing unanimous support for seclusion and little 
Table 3. Perceived benefits of restrictive practices by group

\begin{tabular}{|c|c|c|c|c|c|}
\hline Perceived benefit (valid $N, \%$ ) & $\begin{array}{c}\text { Consumers } \\
n(\%)\end{array}$ & $\begin{array}{c}\text { Carers } \\
n(\%)\end{array}$ & $\begin{array}{c}\text { Professional } \\
n(\%)\end{array}$ & $\begin{array}{l}\text { Total } \\
N(\%)\end{array}$ & $p$-value \\
\hline \multicolumn{6}{|l|}{ Physical restraint } \\
\hline Often/always increases consumer safety $(N=792,68.9 \%)$ & $170(46.5 \%)$ & $126(60.9 \%)$ & $158(71.8 \%)$ & $454(57.3 \%)$ & $<0.001$ \\
\hline Often/always increases staff/others safety $(N=785,68.3 \%)$ & $202(56.4 \%)$ & $133(64.9 \%)$ & $160(72.1 \%)$ & $495(63.1 \%)$ & 0.001 \\
\hline Often/always sets behavioural boundaries ( $N=761,66.2 \%)$ & $150(43.9 \%)$ & $110(53.4 \%)$ & $132(62.0 \%)$ & $392(51.5 \%)$ & $<0.001$ \\
\hline \multicolumn{6}{|l|}{ Mechanical restraint } \\
\hline Often/always increases consumer safety $(N=742,64.5 \%)$ & $132(39.0 \%)$ & $108(54.8 \%)$ & $127(61.3 \%)$ & $367(49.5 \%)$ & $<0.001$ \\
\hline Often/always increases staff/others safety $(N=738,64.2 \%)$ & $211(63.2 \%)$ & $131(66.5 \%)$ & $155(74.9 \%)$ & $497(67.3 \%)$ & 0.018 \\
\hline Often/always sets behavioural boundaries $(N=722,62.8 \%)$ & $114(35.2 \%)$ & $92(46.2 \%)$ & $100(50.2 \%)$ & $306(42.3 \%)$ & 0.001 \\
\hline \multicolumn{6}{|l|}{ Chemical restraint } \\
\hline Often/always increases consumer safety ( $N=773,67.2 \%)$ & $195(55.2 \%)$ & $133(65.2 \%)$ & $167(77.3 \%)$ & $495(64.0 \%)$ & $<0.001$ \\
\hline Often/always increases staff/others safety $(N=769,66.9 \%)$ & $236(68.0 \%)$ & $155(76.0 \%)$ & $187(85.8 \%)$ & $578(75.2 \%)$ & $<0.001$ \\
\hline Often/always sets behavioural boundaries $(N=745,64.8 \%)$ & $119(35.8 \%)$ & $95(47.0 \%)$ & $104(49.3 \%)$ & $318(42.7 \%)$ & 0.003 \\
\hline \multicolumn{6}{|l|}{ Emotional restraint } \\
\hline Often/always increases consumer safety $(N=713,62.0 \%)$ & $64(19.4 \%)$ & $48(25.3 \%)$ & $58(29.9 \%)$ & $170(23.8 \%)$ & 0.022 \\
\hline Often/always increases staff/others safety $(N=706,61.4 \%)$ & $103(32.0 \%)$ & $66(34.9 \%)$ & $69(35.4 \%)$ & $238(33.7 \%)$ & 0.672 \\
\hline Often/always sets behavioural boundaries $(N=697,60.6 \%)$ & $87(27.6 \%)$ & $70(36.7 \%)$ & $65(34.0 \%)$ & $222(31.9 \%)$ & 0.080 \\
\hline \multicolumn{6}{|l|}{ Seclusion } \\
\hline Often/always increases consumer safety $(N=775,67.4 \%)$ & $156(44.1 \%)$ & $117(57.1 \%)$ & $154(71.3 \%)$ & $427(55.1 \%)$ & $<0.001$ \\
\hline Often/always increases staff/others safety $(N=767,66.7 \%)$ & $214(62.4 \%)$ & $148(72.2 \%)$ & $187(85.4 \%)$ & $549(71.6 \%)$ & $<0.001$ \\
\hline Often/always sets behavioural boundaries $(N=751,65.3 \%)$ & $150(44.5 \%)$ & $105(52.0 \%)$ & $135(63.7 \%)$ & $390(51.9 \%)$ & $<0.001$ \\
\hline
\end{tabular}

awareness of harms identified by consumers (Soliday, 1985). More recently in the Netherlands, a survey of the views of 540 psychiatric services staff indicated that nurses and psychiatrists who regularly undertook seclusion rated it as largely positive (Van Doeselaar et al. 2008), whereas consumer experiences of seclusion and restraint are consistently reported as negative (Steinert et al. 2013).

The agreement identified here between stakeholders is a helpful foundation for future practice and policy change, reflecting a more nuanced and shared understanding among key stakeholders. Shared recognition of the significant harms that can be caused by restrictive practices could inform future education, training and organisational change in Australia, building on previous international efforts to change professional attitudes (e.g., Mann-Poll et al. 2013) and create greater awareness. Recent Australian evidence suggests that the notion that restrictive practices are a 'necessary evil' may be modifiable as a consequence of staff training (Mann-Poll et al. 2013, p. 4). Our findings may be indicative of an increased willingness among practitioners to change their use of restrictive practices; an enhanced appreciation of how harmful restrictive practices have been for some consumers may enable further support for those seeking change. An overview of strategies that show promise in reducing the use of seclusion and restraint has been provided by the research team in its report to Australia's National Mental Health Commission (Melbourne Social Equity Institute, 2014). Incorporation of consumer and carer perspectives in staff training could be particularly beneficial in terms of enabling shared recognition of the significant harms experienced (Huckshorn, 2004). If the perceived benefits of restrictive practices are overshadowed by concerns about corrupting the potential for inpatient services to be therapeutic environments, being complicit in human rights breaches and longer term harm associated with trauma, then working towards elimination may become more feasible. Chan (2016) has pointed out that staff safety and human rights are not mutually exclusive and positive behaviour support can be used as a preventive strategy to avoid the use of restrictive interventions. Programs for reducing these practices have previously recognised the need to intervene systemically rather than solely focussing on interventions with individual consumers and others have operationalised a multilevel approach to change (Huckshorn, 2004; Bowers, 2014).

\section{Strengths and limitations}

This is the first ever national Australian survey of beliefs and attitudes regarding seclusion and restraint and, to our knowledge, the only one that has asked the same questions of the three important stakeholder 
Table 4. Perceived feasibility and desirability of eliminating seclusion and restraint, by group

\begin{tabular}{lrrrrr}
\hline Perception of elimination (valid $N, \%)$ & Consumers $n(\%)$ & Carers $n(\%)$ & Professionals $n(\%)$ & Total $N(\%)$ & $p$-value \\
\hline Physical restraint & & & & \\
$\quad$ Desirable $(N=560,48.7 \%)$ & $122(48.8 \%)$ & $53(34.4 \%)$ & $39(25.0 \%)$ & $214(38.2 \%)$ & $<0.001$ \\
$\quad$ Feasible $(N=581,50.5 \%)$ & $87(34.1 \%)$ & $31(19.1 \%)$ & $23(14.0 \%)$ & $141(24.3 \%)$ & $<0.001$ \\
Mechanical restraint $(N, \%)$ & & & & \\
$\quad$ Desirable $(N=608,52.9 \%)$ & $223(80.5 \%)$ & $118(72.8 \%)$ & $121(71.6 \%)$ & $462(76.0 \%)$ & 0.056 \\
$\quad$ Feasible $(N=585,50.9 \%)$ & $199(73.4 \%)$ & $96(61.9 \%)$ & $107(67.3 \%)$ & $402(68.7 \%)$ & 0.044 \\
Chemical restraint & & & & $202(35.8 \%)$ & $<0.001$ \\
$\quad$ Desirable $(N=565,49.1 \%)$ & $116(46.4 \%)$ & $53(35.1 \%)$ & $33(20.1 \%)$ & $151(25.7 \%)$ & $<0.001$ \\
$\quad$ Feasible $(N=588,51.1 \%)$ & $93(35.2 \%)$ & $37(23.4 \%)$ & $21(12.7 \%)$ & & \\
Emotional restraint & $276(90.5 \%)$ & $137(87.3 \%)$ & $149(89.8 \%)$ & $562(89.5 \%)$ & 0.558 \\
$\quad$ Desirable $(N=629,54.6 \%)$ & $234(82.7 \%)$ & $114(78.1 \%)$ & $127(81.9 \%)$ & $475(81.3 \%)$ & 0.498 \\
$\quad$ Feasible $(N=584,50.8 \%)$ & $177(66.8 \%)$ & $92(56.8 \%)$ & $47(31.8 \%)$ & $316(55.0 \%)$ & $<0.001$ \\
Seclusion & $154(56.8 \%)$ & $69(44.5 \%)$ & $40(24.4 \%)$ & $327(55.4 \%)$ & $<0.001$ \\
$\quad$ Desirable $(N=575,50.0 \%)$ & & & & \\
$\quad$ Feasible $(N=590,51.3 \%)$ & & & &
\end{tabular}

groups. It comes at a time when there are increasing calls to reduce and where possible eliminate these practices in mental health settings. Key strengths of the study include the large, national sample including consumers, carers and professionals, and efforts to bring nuance to the debate by considering perceived harms and benefits, and giving separate consideration to the desirability and feasibility of elimination.

One important limitation of the study was convenience sampling, with the sample skewed towards urban

Table 5. Association between lived experience and feasibility/desirability of elimination

\begin{tabular}{|c|c|c|c|c|}
\hline & \multicolumn{2}{|c|}{ Desirable } & \multicolumn{2}{|c|}{ Feasible } \\
\hline & PRR $(95 \%$ CI) & APRR $(95 \% \text { CI })^{*}$ & PRR (95\% CI) & APRR $(95 \% \mathrm{CI})^{*}$ \\
\hline \multicolumn{5}{|l|}{ Physical restraint } \\
\hline Professionals & 1 & 1 & 1 & 1 \\
\hline Carers & $1.33(0.94-1.89)$ & $1.32(0.92-1.90)$ & $1.28(0.77-2.11)$ & $1.24(0.74-2.06)$ \\
\hline Consumers & $1.88(1.39-2.54)$ & $1.72(1.25-2.36)$ & $2.30(1.51-3.49)$ & $1.87(1.20-2.91)$ \\
\hline \multicolumn{5}{|c|}{ Mechanical restraint } \\
\hline Professionals & 1 & 1 & 1 & 1 \\
\hline Carers & $1.02(0.89-1.17)$ & $1.05(0.91-1.20)$ & $0.91(0.77-1.07)$ & $0.93(0.78-1.10)$ \\
\hline Consumers & $1.12(1.00-1.26)$ & $1.12(0.99-1.27)$ & $1.08(0.95-1.23)$ & $1.05(0.91-1.21)$ \\
\hline \multicolumn{5}{|c|}{ Chemical restraint } \\
\hline Professionals & 1 & 1 & 1 & 1 \\
\hline Carers & $1.69(1.16-2.46)$ & $1.87(1.25-2.79)$ & $1.71(1.04-2.83)$ & 1.79 (1.06-3.02) \\
\hline Consumers & $2.23(1.60-3.12)$ & $2.25(1.57-3.23)$ & $2.71(1.76-4.18)$ & $2.13(1.34-3.37)$ \\
\hline \multicolumn{5}{|c|}{ Emotional restraint } \\
\hline Professionals & 1 & 1 & 1 & 1 \\
\hline Carers & $0.98(0.90-1.06)$ & $0.99(0.92-1.08)$ & $0.96(0.86-1.07)$ & $0.97(0.87-1.09)$ \\
\hline Consumers & $1.01(0.95-1.08)$ & $1.03(0.95-1.10)$ & $1.00(0.91-1.10)$ & $1.03(0.93-1.14)$ \\
\hline \multicolumn{5}{|l|}{ Seclusion } \\
\hline Professionals & 1 & 1 & 1 & 1 \\
\hline Carers & $1.79(1.36-2.35)$ & $1.79(1.35-2.36)$ & $1.79(1.29-2.49)$ & 1.69 (1.21-2.34) \\
\hline Consumers & $2.10(1.63-2.71)$ & $1.89(1.45-2.46)$ & $2.31(1.72-3.09)$ & $2.00(1.48-2.72)$ \\
\hline
\end{tabular}

PRR, prevalence risk ratio; APRR, adjusted prevalence risk ratio.

*Model adjusted for gender, age, Indigenous status, state of residency, urbanicity and education level. 
settings and the most populous states of Australia. However, study analyses were adjusted for urbanicity and non-random survey sampling. Members of the professional group were not asked to specify whether they had participated in or overseen the use of seclusion and restraint or whether they worked in general with consumers and carers. An analysis of these subgroups would have offered useful comparative data. Analyses were confined to responses from Australian participants and it may be that beliefs and attitudes differ in other countries. Participants were by definition sufficiently motivated to complete the voluntary survey, and as a result, individuals with strong views regarding seclusion and restraint were probably over-sampled. Another limitation is that despite providing participants with clear definitions of seclusion and each form of restraint, their responses cannot be guaranteed to reflect these definitions. Finally, this study did not examine attitudes towards restrictive practices in specific contexts or settings (e.g., emergency departments, prisons), despite that elimination of such practices is likely to be more easily achieved in some settings than others. Exploration of settingspecific attitudes to seclusion and restraint would be a fruitful avenue for future research.

\section{Conclusion}

A national survey of consumers, carers and professionals indicated differences in attitudes about whether or not seclusion and restraint can be eliminated. However, there was strong agreement that the use of seclusion and restraint can be harmful because of breaches to human rights, compromising therapeutic relationships and trust and people experiencing trauma or being re-traumatised. On the other hand, some benefits were identified and there were differences of opinion about the desirability and feasibility of elimination of these practices. In the case of emotional restraint, there was consensus that it both could and should be eliminated from current practice. These findings are a resource to the field for the continued work of reducing restrictive practices.

\section{Acknowledgements}

The authors thank Andrew Butler for his research assistance with this paper. They also thank all the research participants and agencies that supported the research.

\section{Financial Support}

This work was supported by funding from the National Mental Health Commission. Stuart Kinner is supported by NHMRC Senior Research Fellowship \#1078168.

\section{Conflict of Interest}

This article presents independent research carried out under the auspices of the Melbourne Social Equity Institute. The views expressed in this article are those of the authors and not necessarily those of the National Mental Health Commission. The authors declare that there is no conflict of interest.

\section{Ethical Standard}

The authors assert that all procedures contributing to this work comply with the ethical standards of the relevant national and institutional committees on human experimentation and with the Helsinki Declaration of 1975, as revised in 2008.

\section{Availability of Data and Materials}

Access to the data is subject to multiple ethics approvals, and as such the authors do not have the authority to grant access. Individuals wishing to access the data should contact Stuart Kinner (s.kinner@unimelb.edu. au) in the first instance.

\section{References}

Barton SA, Johnson R, Price LV (2009). Achieving restraintfree on an in-patient behavioural health unit. Journal of Psychosocial Nursing and Mental Health Services 47, 34-40.

Bowers L (2014). Safewards: a new model of conflict and containment on psychiatric wards. Journal of Psychiatric and Mental Health Nursing 21, 499-508.

Bowers L, James K, Quirk A, Simpson A, SUGAR, Duncan S, Hodsoll J (2015). Reducing conflict and containment rates on acute psychiatric wards: the Safewards cluster randomised controlled trial. International Journal of Nursing Studies 52, 1412-1422.

Brophy LM, Roper CE, Hamilton BE, Tellez JJ, McSherry BM (2016a). Consumers and their supporters' perspectives on poor practice and the use of seclusion and restraint in mental health settings: results from Australian focus groups. International Journal of Mental Health Systems 10, 1-10. doi: 10.1186/s13033-016-0038-x.

Brophy LM, Roper CE, Hamilton BE, Tellez JJ, McSherry BM (2016b). Consumers' and their supporters' perspectives on barriers and strategies to reducing seclusion and restraint in mental health settings. Australian Health Review. Published online 3 March 2016, 1-6. http://dx.doi.org/10. 1071/AH15128

Burns T, Rose D (2013). How can the service user voice be best heard at psychiatric meetings? British Journal of Psychiatry 203, 88-89. 
Chan J (2016). Challenges to realizing the Convention on the Rights of Persons with Disabilities (CRPD) in Australia for people with intellectual disability and behaviours of concern. Psychiatry, Psychology and Law 23, 207-214.

Department of Social Services (2014) National Framework for Reducing and Eliminating the use of Restrictive Practices in the Disability Service Sector. Commonwealth of Australia: Canberra.

Gerace A, Pamungkas DR, Oster C, Thomson D, MuirCochrane E (2014). The use of restraint in four general hospital emergency departments. Australasian Psychiatry 22, 366-369.

Huckshorn K (2004). Reducing seclusion and restraint use in mental health settings: core strategies for prevention. Journal of Psychosocial Nursing and Mental Health Services 42, 22-33.

Kumble S, McSherry B (2010). Seclusion and restraint: rethinking regulation from a human rights perspective. Psychiatry, Psychology and Law 17, 551-561.

LeBel J, Stromberg N, Duckworth K, Kerzner J, Goldstein R, Weeks M, Harper G, LaFlair L, Sudders M (2004). Child and adolescent inpatient restraint reduction: a state initiative to promote strength-based care. Journal of the American Academy of Child and Adolescent Psychiatry 43, 37-45.

Lewis M, Taylor K, Parks J (2009). Crisis prevention management: a program to reduce the seclusion and restraint in an inpatient mental health setting. Issues in Mental Health Nursing 30, 159-164.

Mann-Poll PS, Smit A, Van Doeselaar M, Hutschemaekers GJM (2013). Professionals' attitudes after a seclusion reduction program: anything changed? Psychiatric Quarterly 84, 1-10.

McSherry B (2008). Protecting the integrity of the person: developing limitations on involuntary treatment. In International Trends in Mental Health Law (ed. B McSherry), pp. 111-124. Federation Press: Liechhardt.

McSherry B, Gooding P (2013). Torture and ill-treatment in health care settings: lessons from the United Nations. Journal of Law and Medicine 20, 712-718.

Melbourne Social Equity Institute (2014) Seclusion and Restraint Project Final Report to the National Mental Health Commission.

Murphy T, Bennington-Davis M (2005). Restraint and Seclusion: The Model for Eliminating Their Use in Healthcare. HCPro Inc: Marblehead.

National Association of State Mental Health Program Directors (2008). Six core strategies for reducing seclusion and restraint use. Retrieved 22 February 2016 from http:// www.nasmhpd.org/content/six-core-strategies-reduceseclusion-and-restraint-use.

National Mental Health Commission (2012). A contributing life: the 2012 national report card on mental health and suicide prevention. Retrieved 22 February 2016 from http:// www.mentalhealthcommission.gov.au/media/39273/nmhc_ reportcard_lo-res.pdf.

National Mental Health Consumer and Carer Forum (2009). Ending seclusion and restraint in Australian mental health service. Retrieved 22 February 2016 from https://nmhccf. org.au/sites/default/files/docs/seclusion_restraint.pdf.

O'Hagan M, Divis M, Long J (2008). Best practice in the reduction and elimination of seclusion and restraint; Seclusion: time for change. Retrieved 22 February 2016 http://www.tepou.co.nz/uploads/files/resource-assets/BestPractice-in-the-Reduction-and-Elimination-of-Seclusionand-Restraint.pdf.

Putkonen A, Kuivalainen S, Louheranta O, Repo-Tiihonen E, Ryynänen O, Kautiainen H, Tiihonen J (2013). Clusterrandomized controlled trial of reducing seclusion and restraint in secured care of men with schizophrenia. Psychiatric Services 64, 850-855.

Roper C, McSherry B, Brophy L (2015). Defining seclusion and restraint: legal and policy definitions versus consumer and carer perspectives. Journal of Law and Medicine 23, 297-302.

Smith GM, Davis RH, Bixler EO, Lin H, Altenor A, Altenor RJ, Hardentstine BD, Kopchick GA (2005). Pennsylvania state hospital system's seclusion and restraint reduction program. Psychiatric Services 56, 1115-1122.

Soliday SM (1985). A comparison of patient and staff attitudes towards seclusion. Journal of Nervous and Mental Disease 173, 282-291.

Statacorp (2015). Stata Statistical Software: Release 14. StataCorp LP: College Station.

Steinert T, Birk M, Flammer E, Bergk J (2013). Subjective distress after seclusion or mechanical restraint: one-year follow-up of a randomized controlled study. Psychiatric Services 64, 1012-1017.

Sullivan AM, Bezmen J, Barron CT, Rivera J, Curley-Casey L, Marino D (2005). Reducing restraints: alternatives to restraints on an inpatient psychiatric service - utilizing safe and effective methods to evaluate and treat the violent patient. Psychiatric Quarterly 76, 51-65.

The Royal Australian and New Zealand College of Psychiatrists (2010). Minimising the use of seclusion and restraint in people with mental illness: Position Statement 61. Retrieved 22 February 2016 https://www.ranzcp.org/ Files/Resources/College_Statements/Position_Statements/ ps61-pdf.aspx.

Van Doeselaar M, Sleegers P, Hutschemaekers G (2008). Professionals' attitudes toward reducing restraint: the case of seclusion in the Netherlands. Psychiatric Quarterly 79, 97-109.

Zou G (2004). A modified poisson regression approach to prospective studies with binary data. American Journal of Epidemiology 159, 702-706. 